\title{
Improving the Spelling Skills of Students with Learning Disabilities using Apps on the iPad
}

\author{
Linda Chmiliar \\ Athabasca University, Canada
}

\begin{abstract}
In the last few years, use of the iPad for learning has made its way into inclusive classrooms. However, little research data on the effectiveness of this device as a learning tool for students is documented in the literature. It is important for educators to be aware of how the tool can be used in the classroom, and how it be used to enhance classroom instruction. This paper presents findings of a study exploring the use of Simplex Spelling Phonics apps in two classrooms of students with learning disabilities. The results indicate that the apps were very effective in helping students to develop spelling skills. In addition, it was evident that the apps were easily implemented and could provide differentiated spelling instruction and practice in the inclusive classroom.
\end{abstract}

\section{Introduction}

This paper presents findings of a study exploring the use of Simplex Spelling Phonics apps with students with learning disabilities in two classrooms specializing in the instruction of students with learning disabilities. The participants were 23 grade 8 students with learning difficulties in language arts. The students used the Simplex Spelling apps on the iPad, with headphones, for 10 -15 minutes a day, for approximately $1-2$ days a week, for 18 weeks. The student's spelling skills were assessed at the beginning, and end of the study. The study focused on the use of Simplex Spelling Phonics 1 and 2 apps however, several students who completed the Simplex Spelling Phonics 2 app were able to move on to the Simplex Spelling Phonics - Advanced app during the study. This paper describes: the qualitative study that was employed; how the Simplex Spelling apps were used by the students to learn spelling in the classroom; the spelling achievement of the students before and after the use of the apps; any difficulties that were experienced and how difficulties were overcome; and student and teacher perspectives on the use of the apps.

\section{Background}

Over the past several decades, educators have explored the use of digital technology to teach and support students with learning disabilities in classrooms. While students have experienced success with many digital devices, the technological world is constantly evolving with new technologies coming to the forefront. A more recent technological innovation, the iPad, is beginning to make its way into classroom settings, however little research data on its effectiveness as a learning tool is documented in the literature. This study seeks to add to the research data by focusing on how apps designed to teach spelling through a phonics-based approach impact student learning in the classroom.

This study focused on students with learning disabilities. The term 'learning disability' is very complex, and the difficulties experienced can have a life-long impact on the individual. The National Centre for Learning Disabilities [1] explains that learning disabilities are a group of disorders which "affect the brain's ability to receive, process, store, respond to and communicate information" (p.1). Most commonly, learning disabilities are described as a gap between the person's ability, and their demonstrated performance [2]. Within an educational context, learning disabilities often impact a student's abilities in reading, writing, and spelling. These skills are often intertwined, and a disability in one area may manifest difficulties in another area [3]. One of the areas that students with learning disabilities frequently experience difficulties with is spelling. There are many reasons why a person may not be a proficient speller, however in the case of a student with a learning disability, Eden, Shamir and Fershtman [4] note, "the reasons for poor spelling range from difficulties with executing and regulating the processes, deficiency in phonological processing, a slow learning pace, attention deficits, general motor coordination deficiencies, intersensory integration disorders, reading and writing difficulties and motivational factors" (p. 251). Wanzek et al. [5] further explain, that students with learning disabilities often do not have an understanding of the underlying phonological 
structures of language which contributes to their poor spelling ability, and therefore recommend explicit spelling instruction for these students. Among the recommendations, these authors emphasize the use of technology to help students develop their spelling skills.

Historically, the focus in the research literature on technology and learning disabilities has been on the use of assistive technology to support students. Assistive technology refers to any tool or equipment that is used to increase the capabilities on an individual with a disability. Assistive technology is generally divided into three categories: low, mid and high-tech, depending on the level of complexity of the device. An example of a high-tech device would be a digital laptop or tablet device, as they are more expensive and require a more complex power source [6]. There is some research evidence to demonstrate the effectiveness of digital technology in supporting students with learning disabilities. For example, Speech Recognition Software is able to aid struggling writers in producing longer and more complex written work than could be created using traditional handwriting or word-processing modalities [6]. Electronic concept mapping programs or outlines used by students to insert or revise previous work to help them organize their thoughts in a more effectively can be useful [7] Struggling readers have been shown to benefit from text-tospeech software programs that read content aloud to the user. These programs have demonstrated improvements in comprehension, fluency, and accuracy as the user can then focus on the meaning behind the text instead of expending energy on decoding [8]. In their study of middle-school students with learning disabilities, those who completed a composition with the aid of spell-check were able to accurately correct 37 percent of their errors, in comparison to their peers who were not permitted spell-check who accurately corrected only 9 percent of errors [9]. Wanzek et al. [5] also note that spelling instruction that occurs through the use of Computer Assisted Instruction (CAI) has been shown to be effective, most likely because of the personalized instruction and immediate feedback provided by these programs. With many devices it is also possible to provide the student with many options to personalize their device to their individual needs, and permits students to feel as though they "fit in" with their peers, as it is generally considered socially acceptable to complete one's assignments on a computer [6]. It is also important that students learn how to use technology to overcome the deficits caused by their disability, as not only are these skills essential to academic success. In fact, students require a level of technological literacy to prepare them for careers demanding technological aptitude. Further, technology has become a facet of everyday life, from sending text-messages and emails to friends, to submitting typed compositions during school or work, even to playing video games through various consoles and devices [10].

Although there is a body of literature on the use of assistive technology to support students with learning disabilities, very little data exists on the use of mobile technologies. Peterson-Karlan [11] notes that within the realm of technology, the education system often shows a tendency to latch on to a particular device, and not move on despite technological advancements. For this reason, this author advocates for an examination of tools to help students overcome barriers imposed by their disability. Further, Kukulska-Hulme [12] identifies that mobile devices may be an appropriate solution, as they have been demonstrated to improve student learning and engagement.

Mobile technologies, such as tablet computers, are becoming increasingly more common in today's society. The iPad may be one of the mobile technologies that should be considered for use with students with learning disabilities. There are many benefits to tablets such as an iPad. They are smaller, thinner and lighter than a conventional laptop, making them highly portable. The touch screen is naturally intuitive, requiring little training and practice to master, and can be easily viewed from most angles. This device also has a quick start-up time, and extensive battery life, permitting the user greater access to the technology [13]. Additionally, Kukulska-Hulme [12] indicate that the availability of the iPad makes it "cool" for students to use, promoting higher participation in learning tasks and identifies mobile devices as a means for students to determine their own "educational adventure" by following their personal interests in a reflective manner. Learners with learning disabilities may benefit from the use of mobile technologies as a learning tool, by becoming more independent learners, as well as learning academic skills. With these benefits in mind, it is important to research the use of iPads with students with/without learning disabilities. Currently, the research literature is very limited, and requires inquiry into the specific benefits, as well as long-term effects of the use of mobile technologies such as the iPad in the classroom. This study seeks to add to this very limited body of knowledge by examining how apps designed to teach spelling through a phonics-based approach on an iPad, can support students with learning disabilities in the classroom. It is very important at this point in time, as iPad use for learning is becoming more prevalent in schools and classrooms, that data regarding the efficacy of this tool for learning is documented. It is also very important that the use of apps, such as the Simplex Spelling apps, be explored and their impact on learning published for educators. When schools and teachers select apps for their students for use in the 
inclusive classroom, apps with demonstrated efficacy in promoting learning should be considered.

\section{Method}

A total of 23 grade eight students, in two separate classroom groups, and their teacher participated in this research. To initiate this study, the teacher conducted the Schonell Spelling Test Form A on January 10th. Once the results were reviewed, the teacher determined that students scoring a grade equivalent of 6.0 or less would start on the Simplex Spelling Phonics 1 app. Students scoring over 6.0 were started on the Simplex Spelling Phonics 2 app. Before the students began work on the apps, the teacher provided a short demonstration for the students on how to use the apps. For the remainder of the 18-week period the students worked independently on the apps on the iPads. The students were observed weekly as they used the apps, and were asked to share their perspectives on the app use. The students used the apps for approximately $10-15$ minutes on one or two days a week. At the conclusion of the study, the teacher administered the Schonell Spelling Test Form B on May $23^{\text {rd }}$. The teacher completed an interview at the beginning of the study, and her feedback and perspectives were recorded throughout the study.

The central question for this research study was:

- What improvement in spelling skills do the students display while using the apps over? an eighteen-week period of time?

The research also explored the following additional questions:

- How can the Simplex Spelling Phonics 1 \& 2 apps be integrated into classroom instruction to teach spelling?

- How do the students in the classroom use the apps for learning?

- What are the students' perspectives on the use of the apps for learning?

- What is the teacher's perspective regarding the use of the apps for learning and the performance of the students?

This was a qualitative research study that employed an observational case study design [4]. The case study is a methodological approach that involves the in-depth exploration of a specific bounded system, utilizing multiple forms of data collection to systemically gather information on how the system operates or functions. In this study, the bounded system was - two classes of grade 8 students (23 students total), and their teacher in a Learning Strategies class using the Simplex Spelling apps.

Within this primary case study of these 2 classrooms, a layered multiple case study approach is nested. Multiple-case design, or collective case design, refers to case study research in which a number of instrumental bounded cases are selected to develop a more in-depth understanding of the phenomena than a single case can provide [5]. The unit of analysis in this multiple approach was each student participating in the study. These cases were then compared and contrasted to discover themes related to the use of the spelling apps.

In an observational case study, the major datagathering technique is participant observation supplemented with formal and informal interviews, and review of documents [4]. In the present study, classroom observation was used to develop a description of the classroom setting and the physical environment. Observations of the students using the apps occurred on a weekly basis. Document review was another method of data collection utilized. The results of each student's teacher assessments related to spelling were reviewed. The teacher conducted a spelling assessment that consisted of the Schonell Spelling Test Form A in January and Form B in May. This spelling test was chosen by the teacher, as the teacher would normally use the test in her class to determine spelling levels and areas the students were having difficulty with, and the test is widely used in schools across Canada and the United States. A decision was made to use this test and not a standardized measure for the research, as the research was only for an 18-week period of time, and test scores from standardized measures may not reflect any change in spelling skills after that short period of time.

Two types of interviews were used for data collection. Informal interviews that resemble casual conversations occurred in the classroom with the students. The purpose of these conversations was to see how the students were using the apps, and to ask the students what they thought about their learning as they used the apps. An informal interview approach also occurred throughout the study with the teacher. These informal interviews focused on the instructional aspects of the app implementation.

A semi-structured interview was conducted with the teacher at the beginning of the study. At the beginning of the research, the interview questions were used to gather information on the perspective of the teacher as she begins this project. The interview included questions on the approach the teacher was taking and why, how the students were placed into the levels on the apps, which supports were used and why. Further information was gathered during informal conversations with the teacher in the classroom as the research progressed.

As the purpose of the primary case and the multiple individual cases was to gather comprehensive, systematic and in-depth information about each case. Each individual case consists of all of the interview data, field notes, and observations of the students, teacher, and the classroom, the 
classroom spelling assessment of each student before and after the study. The data is organized into a description that includes all of the major information that was then edited, parts fitted together, and organized topically. Each individual case consists of a description of the student's experience with the apps. Finally, the case studies are integrated across cases, exploring the common threads and differences between the students. This paper reviews a number of the common threads identified across the cases. This leads to a discussion and recommendations.

\section{Results}

Overall, the spelling test results indicate that the students evidenced a very strong increase in spelling skills during the research. The average grade level change in the spelling performance of all the students involved in the study over the 18 weeks was 1.9 . The spelling performance change ranged from 0 grade levels to a change of 4.4 grade levels. The greatest change in spelling performance was evidenced by the students scoring the lowest scores initially.

The results from each student case study are presented below.

Student A was a very outgoing, talkative boy that enjoys school and takes time to complete tasks. On the first test his spelling score was grade 6.5. On the final test the student scored grade 8.0. The student found the app easy to use and was able to complete the levels without much trouble. When asked if he enjoyed working with the app he replied, "I think it's pretty cool and a different way to learn how to spell. The spacing of the blocks and the hearing the different sounds of the words really helps me." Although it did take him a little longer to spell the words in the app, he indicated that he has to think about the word then he said he repeats it to himself before he enters the letters. He said, "I just want to make sure I know how it sounds first."

Student B was also a very outgoing, talkative boy, but he has a hard time staying on task. He tends to disturb those around him and needs to be told continually to stay on task. When working with the apps he had a hard time staying focused on what he was doing for long periods of time. On the first test his spelling score was grade 3.1. On the final test, the student scored grade 4.7. Even though it did take him a while to get through the levels in the apps, it is clear that he still benefitted from the use of the apps. This student required directions and support when learning how to use the app and go through the levels. During the study an app update occurred that resulted in changes to the look and feel of the app. The student expressed some concerns that, "the letters changed and got really small." "When the buttons got smaller I had a hard time pressing the wrong buttons." As the student went through the app he said that, "the words are getting harder but if I go slow and sound it out it hasn't been too hard yet." He also indicated that "I know how many letters the word has from the boxes so that makes it a bit easier, but when the words are long it's harder, I like it better when the words are short."

Student $\mathrm{C}$ was a quiet boy that always looks like he puts a lot of effort into his schoolwork. He enjoys being at school and hanging out with his friends. On the first test his spelling score was grade 4.4. On the final test the student scored grade 6.2. This student required additional support with the explanation of the app as well as how to properly use it. He also had some trouble understanding the voice that read the words and often needed clarification of the word. Sometimes he repeated the word verbally several times. He liked that he was able to drag the letters as well as move them around. He said, "I like that you can see if they are correct right away and don't have to wait." He spent a great deal of time going back to make sure that he was spelling the words correctly.

Student D was girl who appears to really enjoy school. She works well individually and in groups and always finishes her assignments on time. On the first test her spelling score was grade 8.8. On the final test the student scored grade 9.9. This student did not require any specific one-on-one support with the use of the app and flew through most of the levels correctly. She found that the app was pretty easy to use and beneficial, although she did find she was having trouble with homonyms and hearing the words correctly. Because she had difficulties hearing the word, this student indicated that she liked the option to repeat the word. She said, "Sometimes it's hard to hear the lady so I have to replay it." She also enjoyed the fact that she could move around the letters if the word was spelled incorrectly, "I like how you can redo it if it's wrong or if the letter is in the wrong place." She did find the navigation very touchy and spoke about accidentally hitting the wrong letters. She said, "The boxes are also really helpful and it makes it easier to know which word has how many letters."

Student E was a boy who tended to become distracted easily and frequently had a hard time staying on task and completing assignments on time. On the first test his score was grade 2.2. On the final test the student scored grade 6.6. This student did not require any specific one-on-one support with the use of the app. However, this student became bored and frustrated when we worked for long periods of time, "Can we be done this now?" When this student got to higher levels he wanted to work on the app less and less. It is likely that as the words became more difficult, he found it difficult to maintain his motivation when working on the app.

Student $F$ was a girl that appears to put considerable time and effort into completing her work, although she can become very distracted by 
the people around her. Unfortunately, this distraction results in her taking a long time to complete her assignments. On the first test her spelling score was grade 4.9. On the final test the student scored grade 7.8. Although the student would get distracted easily and may not have made the most productive use of the time given to use the app, her spelling skills improved. This student found the voice a bit distorted and sometimes had to clarify that she heard the word correctly. But once she was able to correctly identify the words, she found that the app was very beneficial, "The app really helps me to remember the different sounds for different words." She found that once she was able to hear the sounds of the words after repeating them, the spelling became much easier. This student tended to skip through the tests and indicated that she was continually was unsure of the level she was on. She frequently searched through the app to make sure she was on the right activity. When asked how difficult the app was to use she replied, "It's medium, I know some of the words, but sometimes I put the wrong letters." She found that some of words sound the same but are spelled differently, so she had to base the spelling on the definitions. When asked why this was occurring she replied, "I just need to go a bit slower and listen to the words more carefully."

Student $\mathrm{G}$ was a quiet boy that likes to sit on his own so that he has enough space to complete his work independently. He enjoys working at his own pace and not being pushed to complete tasks too quickly. Although he works slower than some of the other students, he takes pride in what he does and tries to make sure that his work is done to the best of his ability. On the first test his spelling score was grade 7.0. On the final test the student's score was grade 8.4. When this student used the app at the beginning of the study, he required support to learn how to work through the app. For example, he had many specific questions on how to use the app and he had difficulties understanding many of the words. Throughout the study this student worked hard to make sure that he did well on the app. This student began at the Simplex Spelling 2 app and was able to move forward to use the advanced version. This student reported that, "using the app is much easier than writing spelling tests." This student doesn't enjoy the feeling of using paper and pen and prefers the use of the iPad. He expressed his frustrations with accidentally tapping the wrong letter when spelling and the app identifying the word as incorrect before he had finished spelling it. He enjoyed being able to see the word on the screen and to verify different combinations of the spelling to visually see how the word was spelled. He reported that he liked, "Using the hints but I still find some of the words hard. It's not too much the spelling but more so the placing of the letters on the screen. I know which letters to use but sometimes I am just unsure of the exact order they go in, so seeing them all is helpful. I also think that the app is easy to understand." When the student got frustrated he began to rush through the app, making many errors.

Student $\mathrm{H}$ was a boy who appears to take pride in his work but can easily become distracted by the students around him. On the first test his score was grade 3.8. On the final test the student scored grade 6.3. This student did not require any specific one-onone support with the use of the app, but he was easily distracted and may not have made the most productive use of the time given to use the app. He used the hints that were provided in the app when he was having difficulties, but still had a hard time placing the letters. Once the letters were placed (even if incorrectly placed) he found it easier to move them around rather than choose them from the keyboard. He stated, "I know which letters should be used in the word, I just have a hard time picking them out when all the letters are there. So I just choose the ones I think should go there then I move them around." When the student became distracted he went through the words very quickly and did not make much use of the definitions or explanations of the words. Instead of making sure the words were spelled correctly, he just wanted to finish the levels.

Student I was a very outgoing girl who takes time to complete her work with care and finishes assignments on time. On the first spelling test her score was grade 5.0. On the final test the student's score was grade 6.6. She had a few clarifying questions about using the app and experienced some difficulties understanding the voice. When asked what she thought of the differences between the Simplex Spelling apps 1 and 2 and if they were helpful she replied, "the syllables make it a lot easier than the first one because it's a lot clearer and they say the word slower in certain places, so even though the words are longer, the syllables make it better."

Student $\mathrm{J}$ was an outgoing girl who appears to take a lot of pride in her work. She spends a lot of time completing tasks and due to the increased amount of time she takes to complete assignments they are not done on time. On the first test her score was grade 5.7. On the final test this student scored grade 7.0. She had many questions during the study about how to use the app and how to maneuver through the differing levels. When asked how she felt the app was helping her she replied, "I like it, but some of the words are too easy because I already know how to spell them, I like that I can see all the letters, that makes it much easier to think about which letters need to be used to spell the word correctly." When she was asked about what she liked about the app she replied "I like that I can go fast and still get the words right, it's easier than writing because I get to use the keyboard." This student reported that, "the pronunciation of the speaker is 
sometimes hard to understand but that's the only part that's difficult so far."

Student K was an outgoing boy who often needs extra time to complete tasks. On the first test his score was grade 7.8 . On the final test her score was grade 7.8. This student was able to attempt all 100 words on the second test in comparison to only attempting 83 words on the first test. This student did not require any specific one-on-one support with the use of the app. He was able to listen to the initial instructions and go through the use of the app on his own in a timely fashion. When the student began to use the app it was evident during the observations that he was really listening carefully to the words and how they were used in the sentences that were provided. He put the time in to make sure that he was using the app effectively and going back through the words that he had spelled incorrectly. This student reported, "I have to listen to how the words are used and sometimes repeat them to make sure that I know what the word is before I begin to spell it."

Student L was a boy who is very social and hard working. He works hard to complete his assignments on time and make effective use of his classroom time. On the first spelling test his score was grade 7.2. On the final test the student's score was grade 8.0. This student did not seem to have any troubles working through the app and expressed that he enjoyed having the opportunity to work independently. He indicated that he had some troubles getting used to the keyboard but once he was used to where the letters were placed it became easier. This student reported, "I find it a bit easier than writing, and I think that it has helped me visualize the words when writing a bit better."

Student $\mathrm{M}$ was a girl that gets bored quickly with the work at hand and also tends to get distracted easily. On the first spelling test her score was grade 6.5. On the final test the student's score was grade 8.6. She worked through the app and had little difficulty with the navigation. She had some troubles hearing and understanding the voice on the app but appeared to have fewer concerns the more she used the app. This student found the app helpful in her learning, but got frustrated with double tapping the letters by accident. She said she found the app quite easy to use and felt she was doing well. "I like that there are definitions that makes it easier to know the word."

Student $\mathrm{N}$ was a boy who works well independently and appears to take a lot of pride in his work. He likes to have his own space when working and doesn't like when others around him try to distract him. On the first spelling test her score was grade 4.9. On the final test the student's score was grade 6.8. The student needed clarification of the instructions at the beginning of the study, but once he got going working through the app, he was more confident. The student found the apps helpful and much easier than writing. When he was having some troubles with the silent 'e' he stated, "I just don't hear the "e" but when I know the words I am much quicker at spelling them on the iPad in comparison to when I write the words." He had difficulties going back and spelling the words when they were incorrect and often skipped through without spelling the word correctly. This student was observed to be picking up on the spelling patterns in the different levels and he indicated that he found the sentences a bit easier to understand as the words got more difficult.

Student $\mathrm{O}$ was a boy who works well independently but he can become distracted by students around him. On the first test he scored grade 4.8. On the final test this student scored grade 6.6. This student frequently asked for help with clarifying the pronunciation of the words in the app. He was proud of his results but when asked to describe what he had completed he was not able to. This student indicated that he liked the differences between Simplex 1 and 2 and liked the format of Simplex 2 best. This student indicated that he thought working on the app was helping with his writing. He said, "I'm thinking about how the word looks on the iPad before I write it down." This student also indicated that he was also using this strategy when working on his chrome book. He found the Simplex Spelling apps pretty easy to use and liked being able to listen to the words and the sentences more than once. When he spelled words correctly that were difficult for him, he would call out, "look I spelled this one correctly!" He was very happy with his progress through the app and liked when could see the results right away.

Student $\mathrm{P}$ was a quiet boy who stays on task and is very focused on his work. On the first spelling test his score was grade 8.7. On the final test this student scored grade 8.8. This student listened to the instructions given as to the app use and did not have any specific questions. When asked what he thought about the app he replied, "It's easy!" He was using strategies such as sounding out the words as he worked through the app. He completed the app levels pretty quickly and spelled the words correctly.

Student Q was an outgoing boy who gets off track very easily. When he is working he takes some time to complete tasks, but in the end is able to complete them independently. On the first spelling test his score was grade 6.1. On the final test this student's score was grade 8.3. This student had difficulties learning how to use the app and understanding how it was going to help his spelling. Throughout the use of the app, this student expressed frustration. He indicated, "I'm not hearing the silent letters or I'm spelling them backwards." This student required repeated instructions to work and spell slowly and to make sure that he was using all of the opportunities to help spell each word correctly. He 
had to be continually monitored to ensure that he wasn't going on the new levels without spelling words correctly. He was more concerned with finishing the levels and moving forward, than spelling the words correctly.

Student $\mathrm{R}$ was a quiet girl who was easily distracted by people and things going on around her. On the first spelling test her score was grade 5.9. On the final test this student scored grade 7.8. The student did not have any specific questions when working through the app but it did take her a bit of time to understand how the app worked. This student reported, "I have a hard time with the keypad because it's really easy to accidentally press the same letter twice." She found Simplex Spelling 2 a bit more difficult than the first app. She said, "I find the hints help when I can't understand what she's saying." This student used the hints as a replacement for extra help when she could not understand the pronunciation of the voice. This student reported, "Sometimes I don't understand some of the words because I've never heard them before and the letters are just too close together."

Student $\mathrm{S}$ was a boy who takes the time and effort to complete his work but does get distracted easily by those around him. On the first spelling test his score was grade 3.6. On the final test this student's score was grade 4.9. This student had no real challenges and seemed to be enjoying using the app. This student found using the app relatively easy "the words are pretty easy but using the app and the iPad makes it easier than writing the words down with pencil and paper, it helps to hear the sound of the words and be able to repeat it as many times as you need to."

Student T was a girl who puts a lot of effort into completing assignments. She takes her time to make sure she is completing assignments according to the directions. On the first spelling test her score was grade 7.1. On the final test this student's score was grade 9.0. This student had no questions on how to use the app but seemed really excited to be using the iPad and really interested in what kinds of results would come from it. She said, "It seems like it's going to be a lot of fun!" This student moved through the app confidently and enjoyed it. "The only thing I am finding difficult so far is the typing, I end up hitting buttons that I don't mean to." She referred to the voice sometimes being hard to understand and she had to keep repeating it or ask someone what the speaker was saying, "I've never seen some of these words so I have to sound them out or replay it again because they might say it weird. The typing can be difficult because I always accidentally hit the wrong button."

Student U was a boy who is quiet and likes to take his time when completing his work. On the first spelling test his score was grade 3.6. On the final test this student's score was grade 6.6. This student was really excited about using the app but had no specific questions about how to use it. This student moved through the app confidently and indicated that he enjoyed using it.

Student V was a girl who puts a lot of effort and time into her work and really enjoys doing well. On the first spelling test her score was grade 5.5. One the final test this student scored grade 7.8. This student worked though the app with no troubles except some clarifications on how to delete and change the letters around. She went through Simplex 1 very quickly and was very proud of her accomplishments. She reported, "I find it easy to use but when I try and go fast it gets more difficult because I hit the wrong letters and it's frustrating because I know how to spell it but just accidentally hit the wrong one." She also reported that, "The sentences are also really helpful because sometimes words sound the same but aren't spelled the same, like waste and waist. When they put it in a sentence I know which one they want."

Student W was boy who enjoys working independently, but also gets distracted very easily. On the first spelling test his score was grade 5.2. On the final test this student scored grade 8.6. This student worked though the app in class and reported no difficulties. He talked about his use of an iPad at home and said that this was the reason he was used to using the device. This student went through Simplex 1 very quickly and did a lot of doublechecking to make sure that he had completed the app correctly. "I think that the app is really helping me to spell words, I find it much easier to type on the iPad."

Overall, although the students expressed some concerns about elements in the apps such as the difficulties understanding the voice at times, student comments regarding the use of the app were very positive. In addition, the spelling test results indicate that the students evidenced a very strong increase in spelling skills. The achievement results are summarized in the table below (Table 1).

During the 18-week period a number of observations were made by the researcher and the research assistant as the students used the apps in class. On the positive side, the students appeared to really like using the app for their spelling practice. Many students expressed a preference for working on the iPad, indicating that it was fun and easier to learn with technology.

After a brief introduction on how to use the apps by the teacher, the majority of the students picked up on how to use the app fairly easily and only experienced a few difficulties. For most of the students, the navigation through the app appeared to be quite intuitive. After the first few weeks, the majority of the students worked on the apps independently. Even the students in the study with 
significant attention deficits were able to sustain attention while working on the apps in the classroom.

Table 1. Student spelling scores

\begin{tabular}{|c|c|c|c|}
\hline Student & $\begin{array}{c}\text { First Test } \\
\text { Grade } \\
\text { Level }\end{array}$ & $\begin{array}{c}\text { Final Test } \\
\text { Grade Level }\end{array}$ & Change \\
\hline $\mathrm{A}$ & 6.5 & 8.0 & 1.5 \\
\hline B & 3.1 & 4.7 & 1.6 \\
\hline $\mathrm{C}$ & 4.4 & 6.2 & 1.8 \\
\hline $\mathrm{D}$ & 8.8 & 9.9 & 1.1 \\
\hline $\mathrm{E}$ & 2.2 & 6.6 & 4.4 \\
\hline $\mathrm{F}$ & 4.9 & 7.8 & 2.9 \\
\hline $\mathrm{G}$ & 7.0 & 8.4 & 2.4 \\
\hline $\mathrm{H}$ & 3.8 & 6.3 & 2.5 \\
\hline I & 5.0 & 6.6 & 1.6 \\
\hline $\mathrm{J}$ & 5.7 & 7 & 1.3 \\
\hline $\mathrm{K}$ & 7.8 & 7.8 & 0 \\
\hline $\mathrm{L}$ & 7.2 & 8.0 & .8 \\
\hline $\mathrm{M}$ & 6.5 & 8.6 & 2.1 \\
\hline $\mathrm{N}$ & 4.9 & 6.8 & 1.9 \\
\hline $\mathrm{O}$ & 4.8 & 6.6 & 1.8 \\
\hline $\mathrm{P}$ & 8.7 & 8.8 & .1 \\
\hline Q & 6.1 & 8.3 & 2.2 \\
\hline $\mathrm{R}$ & 5.9 & 7.8 & 1.9 \\
\hline $\mathrm{S}$ & 3.6 & 6.6 & 3.0 \\
\hline $\mathrm{T}$ & 7.1 & 9.0 & 1.9 \\
\hline $\mathrm{U}$ & 3.6 & 4.9 & 1.3 \\
\hline $\mathrm{V}$ & 5.5 & 7.8 & 2.3 \\
\hline $\mathrm{W}$ & 5.2 & 8.6 & 3.4 \\
\hline $\begin{array}{c}\text { Average } \\
\text { Grade } \\
\text { Change }\end{array}$ & & & 1.9 \\
\hline
\end{tabular}

It was evident in observations throughout the research, that the structure and format of the app supported student learning. Observations in class showed that many of the students used the hints provided and listened to the sentences to understand the words. Students really relied on the sentence cues to understand which word they were asked to spell. One student said, "The sentence is really helpful because sometimes words sound the same but aren't spelled the same." Other students commented that they were picking up the patterns in the words as they practiced and they found that the number of boxes provided made it easier to know how to spell a word. Several students also commented that they relied on the color change of the letters that showed when the word was incorrect. This provided them with instant feedback and the opportunity to change their response immediately. They also indicated that they appreciated the opportunity to just change the wrong letter, rather than having to redo the whole word. On many occasions students commented that moving the boxes to spell words was considerably easier for them than the process of writing and that as they were moving the boxes they could focus on the patterns in the words rather than their difficulties with writing. Students said that using the app and the iPad made it easier than writing words down with a pencil and paper

During the observations, a number of concerns were identified. At the beginning of the research, all of the students were skipping through the items moving from level to level within the app and ignoring words that they did not want to practice. When the data from the app was examined this pattern was prevalent for the majority of the students. At that point, the teacher and research assistant explained the use of the app in more detail and reminded students to work through the app item by item. For some students this reminder was sufficient. Many students however continued to skip through the items. Several students continued to not reattempt words that they did not get correct on the first try throughout the study.

Many of the students went through the spelling on the app as quickly as possible. They did not use the hints, did not sound out the words, and appeared to be not focusing in on the word patterns that were presented. After the first week this concern was addressed and the students were encouraged to use the hints and structure of the app to learn the words. This seemed to make a significant impact on some of the students who were then observed to be implementing these strategies. Other students failed to use these strategies for the majority of the study.

A few difficulties were experienced with the placement and function of the letters. Some students had difficulties with the letter placement initially, but indicated that once they learned where the letters were that it got easier. Others students had continuing difficulties with the touch on the letters. Student experienced initial difficulties finding the letters and getting used to the way they work. Several students reported that they found the letters too close together. Other students had difficulties finding and tapping the letters without errors. One girl found the letters easy to use but when she goes "too fast it's difficult because (she)... hits the wrong letter and it's frustrating because (she)... knows how to spell it." Other students commented about getting frustrated with continually hitting the wrong letters. 
One student said that he was, "having a hard time with the keyboard, it's easy to accidentally press the same letter twice."

The teacher in this study has been involved in special education for 14 years. The teacher thought the apps were appropriate for her classrooms and thought that the game like format of the apps would appeal to her students. She also indicated that the apps allowed all of the students to progress through the apps at their own level and pace. The teacher also indicated that she liked the organization of the apps and the emphasis on phonemic awareness, which is very appropriate for students with learning disabilities.

At the conclusion of this research study the teacher was very surprised at the spelling achievement of both her classes of students. She indicated that the results were "well above" what she would normally expect.

\section{Discussion}

The Simplex Spelling apps are a unique series of apps that progress from simple to complex phonetically based spelling practice. This range of spelling words at different levels from grade 1 to middle school level, makes this app series very attractive to teachers who are working to meet a diverse range of student needs in the classroom. The apps could help teachers provide individualized spelling practice to students spelling at different levels in their classrooms. The apps also allow students to work independently at their own pace.

Students enjoyed using the apps and found them "cool" and "fun" to use. They were motivated to use the apps and engage in their weekly spelling practice. Students expressed interest in using the apps more, and several students indicated that they would be willing to practice their spelling at home for homework. This is a departure from pencil and paper spelling practice that students typically find boring and tedious. This allowed the students to work independently on the app in the classroom with very little support and direction from the teacher. Even those students with significant attention difficulties were able to work on the app with minimal direction. Students reported that they liked the features in the apps such as hints. All these features would not be available to them in paper and pencil spelling practice. These features appear to support student learning. Overall, it appears that this series of phonetically based spelling apps could be a very useful tool for teachers in inclusive classrooms who wish to successfully engage in differentiated spelling instruction for their students.

\section{Conclusion}

The use of the apps produced very positive results. The spelling scores of the students were much improved over the two administrations of the Schonell Spelling Test. Even though this is not a standardized measure of spelling, it is typically used in the classroom to assess student spelling and does provide an indication of the students' ability to spell words from word families. The teacher also reported that the student spelling achievement had greatly improved, and that the results exceeded what she would normally expect in the classroom. These results were obtained in busy classroom, not a clinical setting. Although the teacher had some initial support to set up the research project, the monitoring and supervision of app use was primarily done by the teacher. This would seem to indicate that the applicability and usefulness of these spelling apps in the average inclusive classroom is very good.

\section{References}

[1] National Center for Learning Disabilities (2013) "General LD Info", http://www.ncld.org (4 October 2015).

[2] Kennedy, M.J., and D.D. Deshler, "Literacy instruction, technology, and students with learning disabilities: Research we have, research we need", Learning Disabilities Quarterly, 33, 2010, pp. 289-298.

[3] Melekoglu, M.A. "Impact of motivation to read on reading gains for struggling readers with and without learning disabilities", Learning Disability Quarterly, 3, 2011, pp. 248-261.

[4] Eden, S., Shamir, A., and M. Fershtman, "The effect of using laptops on the spelling skills of students with learning disabilities", Educational Media International, 48, 2011, pp. 249-259.

[5] Wanzek, J., Vaughn, S., Wexler, J., Swanson, E.A., Edmonds, M., and A.H. Kim, "A synthesis of spelling and reading interventions and their effects on the spelling outcomes of students with LD", Journal of Learning Disabilities, 39, 2006, pp. 528-543.

[6] King-Sears, M., and A. Evmenova, "Premise, principles, and process for integrating TECHnology into instruction", Teaching Exceptional Children, 40, 2007, pp. 6-14.

[7] Peterson-Karlan, G.R. "Technology to support writing by students with learning and academic disabilities: Recent research trends and findings", Assistive Technology Outcomes and Benefits, 7, 2011, pp. 39-62.

[8] Berkeley, S., and J.H. Lindstrom, "Technology for the struggling reader: Free and easily accessible resources", Technology for Teaching and Learning, 43, 2011, pp. 4855. 
[9] MacArthur, C. A., Graham, S., Haynes, J. A., and S. De La Paz, "Spelling checkers and students with learning disabilities: Performance comparisons and impact on spelling", Journal of Special Education, 30, 1996, pp. 3557.

[10] King-Sears, M., Swanson, C. and L. Mainzer, "TECHnology and literacy for adolescents with disabilities", Journal of Adolescent and Adult Literacy, 54, 2011, pp. 569-578.

[11] G.R. Peterson-Karlan, "Technology to support writing by students with learning and academic disabilities: Recent research trends and findings", Assistive Technology Outcomes and Benefits 7, 2011, pp. 3-62.

[12] A. Kukulska-Hulme, "Limelight on mobile learning: integrating education and innovation", Harvard International Review 54, 2013, pp. 12-16.

[13] P. Pyper, "Get an 'app' for that", Learning Disability Practice 14, 2011, pp. 9-10.

[14] R. Bogan and S. Biklen, Qualitative Research in Education: An Introduction to Theory and Methods. Allyn and Bacon, Toronto, 1998.

[15] L. Chmiliar, "Multi-Case Designs", in A. Mills, G. Durepos, \& E. Wiebe (Eds.), Encyclopedia of Case Study Research, SAGE Publications, Inc., London, 2010.

\section{Acknowledgements}

The author would like to acknowledge IRAP, Canadian National Research Council for their funding for this research. Also, thanks to Craig Welburn and Serena Seeger. 